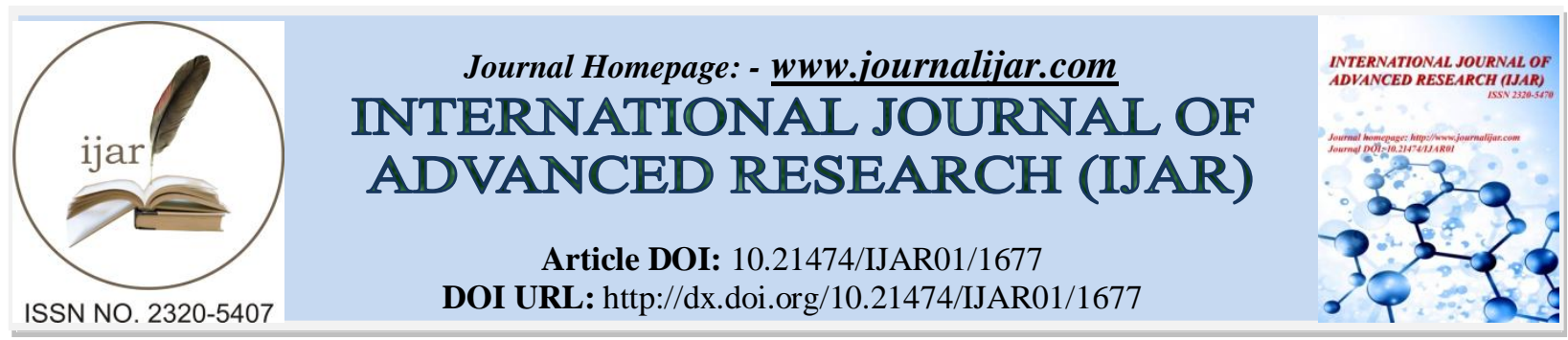

RESEARCH ARTICLE

\title{
FUNCTIONAL TESTING OF VITAMIN D RESPONSE ELEMENTS IN THE LCE2 GENE CLUSTER WITH RELEVANCE TO PSORIASIS.
}

\author{
Abdullah Aljabri ${ }^{1}$, Abdullah Alhazmi ${ }^{1}$, Osama Alateeq ${ }^{1}$, G Kerr Whitfield ${ }^{2}$ and Jui-Cheng Hsieh ${ }^{2}$. \\ 1. College of Medicine, Al Imam Muhammad Ibn Saud Islamic University, Riyadh, Saudi Arabia. \\ 2. Basic Medical Sciences,University of Arizona College of Medicine, Phoenix,Arizona,United States.
}

\section{Manuscript Info}

Manuscript History

Received: 15 July 2016

Final Accepted: 21 August 2016

Published: September 2016

Key words:-

late cornified envelope genes, psoriasis, skin barrier, vitamin D.

\section{Abstract}

Psoriasis is a chronic inflammatory skin disease characterized by abnormal keratinocyte proliferation and differentiation. A genetic risk factor for psoriasis is a deletion of LCE3B and LCE3C genes encoding structural proteins in terminally differentiated keratinocytes, suggesting that compromised skin barrier function has a role in psoriasis susceptibility. Because analogs of 1,25-dihydroxyvitamin $\mathrm{D}_{3}(1,25 \mathrm{D})$ are used in psoriasis treatment, we hypothesized that $1,25 \mathrm{D}$ acts via the vitamin $\mathrm{D}$ receptor (VDR) to upregulate expression of LCE2B genes, potentially mitigating the absence of LCE3B/LCE3C gene products.

Copy Right, IJAR, 2016,. All rights reserved.

\section{Introduction:-}

Psoriasis is a chronic inflammatory skin disease characterized by abnormal keratinocyte proliferation and differentiation[1]. Psoriasis affects 1.5-2\% of the population in western countries [2]. In 1985 a case report was published by (Morimoto S, Kumahara Y) that led us to the conclusion that raising blood 1,25-dihydroxyvitamin D3 $(1,25 \mathrm{D})$ can dramatically improve psoriasis symptoms in some patients [3]. And from that point $1,25 \mathrm{D}$ analogs were developed, including calcipotriene[4] treatment, which are now routinely used as topical agents in psoriasis.

In that point we know that the bioactions of $1,25 \mathrm{D}$ are mediated by vitamin $\mathrm{D}$ receptor (VDR) expressed in many tissues, including skin [5]. However, the specific genes that are regulated by 1,25D to improve psoriasis symptoms have yet to be defined. Genome wide searches for psoriasis susceptibility loci have implicated as many as 36 chromosomal regions [6], including 12 named linkages (PSORS1-12). One of these, the PSORS4 locus, is associated with an assembly of skin differentiation genes on human chromosome 1 [7]. A reported PSORS4 risk allele consists of a deletion encompassing two genes (Fig. 1) encoding late cornified envelope 3B and 3C (LCE3B and LCE3C) proteins [8].

This deletion is found in $63-72 \%$ of patients with psoriasis according to ethnicity [9]. LCE3B and LCE3C belong to a cluster of five LCE3 genes that are expressed late in keratinocyte differentiation, and the protein products of these genes are crosslinked to facilitate formation of the cornified envelope [10]. Transcripts of LCE3A, $-3 \mathrm{C},-3 \mathrm{D}$ and $-3 \mathrm{E}$ are upregulated in psoriasis [11]. Tape stripping to induce superficial skin injury also upregulates LCE3A/3C/3D/3E expression [12]. In contrast, other LCE genes, LCE2B (approximately $71 \mathrm{~kb}$ from the PSORS4 deletion), are expressed at moderate levels in normal skin, but are downregulated in psoriasis or superficial injury [12]. Previous work in our lab showed that the late cornified envelope-2B (LCE2B) gene is upregulated by 1,25D. this may mitigate the absence of LCE3B/LCE3C gene products. 
We hypothesis At least one VDRE in the LCE2 gene cluster binds VDR/RXR and stimulates transcription of the nearby LCE2B gene

In this study we will examine three candidate of vitamin D response element (VDRE) sequences, LCE2.e5 and LCE2.e9 and LCE2.e10, located in the LCE2 gene cluster.

\section{Materials \& Methods:-}

To test this, we used a luciferase plasmid to see if any of these VDREs can regulate luciferase in a 1,25D-dependent manner. And here the steps:

1. plasmid preparation (pSG5-hVDR): E-coli containing the desired plasmids were streaked onto LB-agar plates containing ampicillin and tetracycline for isolation of single colony.

2. Then Single colony were inoculated into TB broth containing ampicillin / tetracycline for overnight growth. After that, Bacteria were collected by centrifugation, and lysed. Plasmid DNA was purified using a midiprep kit (Invitrogen).

3. transfection into HEK293 with Renilla plasmid (this plasmid tells us if the transfection worked): HEK-293 cells were transfected with five LUC vectors: empty Luc, ROC2-Luc, LCE2.e5-Luc, LCE2.e9-Luc and LCE2.e10Luc.

4. treatment with ethanol or 1,25D: Transfected cells were treated for 24 hours with $10^{-8} \mathrm{M} 1,25 \mathrm{D}$.

5. Cell lysis and dual luciferase assay: Each well was lysed and assayed for both firefly and RENILLA luciferase (Dual Luciferase Assay Kit, Promega). LARII solution contains substrate for firefly luciferase, Stop \&GLo contains quencher for firefly luciferase and substrate for Renilla luciferase.

\section{Results:-}
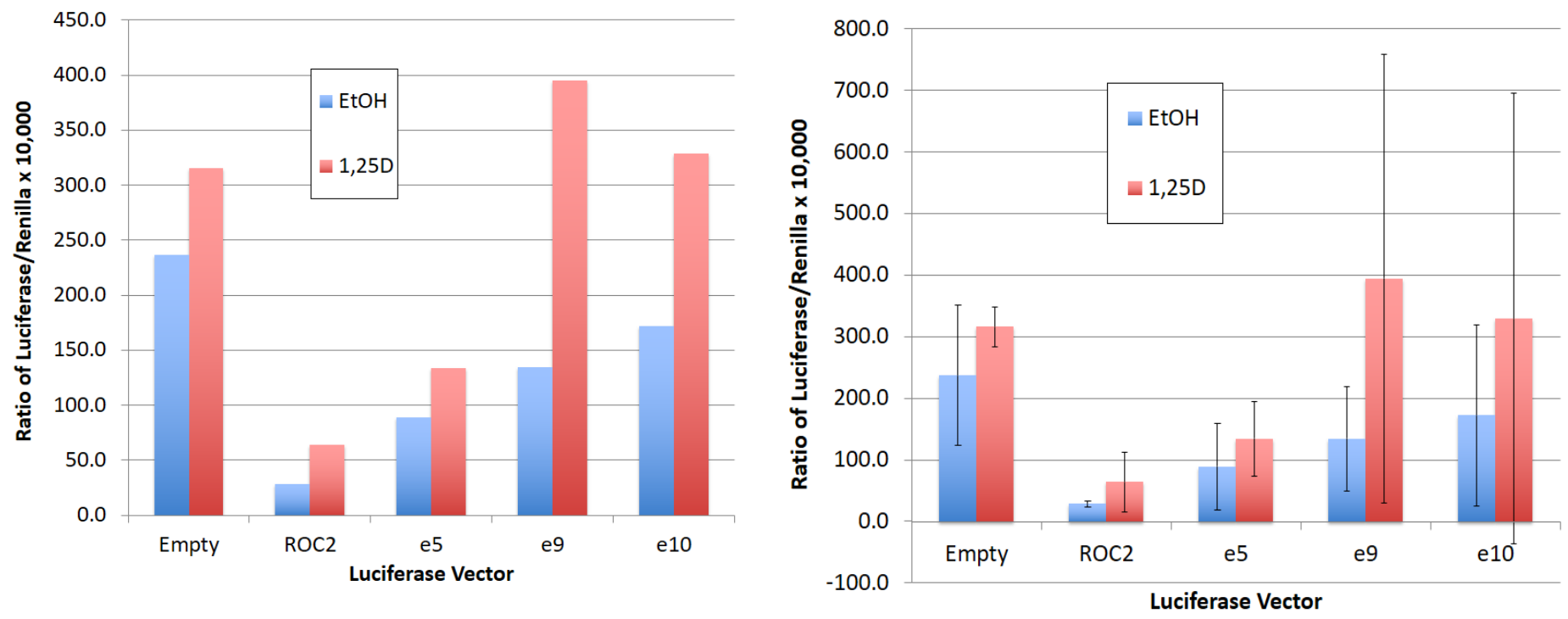

\section{Repeat with ROC2 and e9}

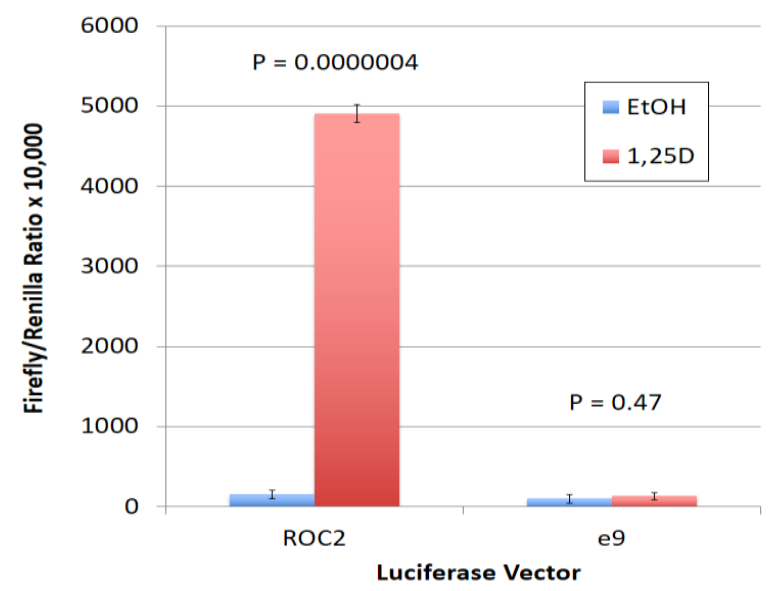


Preliminary data in HEK293 cells (Exp I, Exp II) suggested that all three VDREs appear might be responding to $1,25 \mathrm{D}$ but these results were not statistically significant due to high variability. The LCE2.e9 element was chosen for a second experiment (Exp III) together with the ROC2 control. The second experiment showed high consistency but unfortunately the e9 element, in contrast to the ROC2 element, showed very low activity.

\section{Conclusion:-}

LCE2B (e5, e9, e10) is not significant due to high variability in our assay in our cell lines and using VDR ligands We recommend Future Experiments to Test other LCE2 genes (LCE2A, 2C and 2D) to see if they are also upregulated by 1,25D. and to Repeat our results in HEK293 and other cell lines including keratinocytes.

\section{Acknowledgements:- \\ We would like to thank:-}

Our supervisors: G. Kerr Whitfield, PhD Judi-Cheng Hsieh, PhD And all the people who made the summer research program in imam Muhammad ibn Saud Islamic university possible: Prof. Khalid Alqumezi, Dr. FahadAlateeq, Dr.Sami Al-Daham, MD, Director of International Program Cecilia Rosales, MD, MS, director of Phoenix Programs and an associate professor Dr. Janet Foote from University of Arizona, College of Medicine-Phoenix.

\section{References:-}

1. Parisi R, Symmons DP, Griffiths CE, Ashcroft DM (2013) Global epidemiology of psoriasis: a systematic review of incidence and prevalence. J Invest Dermatol 133:377-385. doi:10.1038/jid. 2012.339

2. johnson, richard. allen. (2009) Fitzpatrick's Color Atlas and Synopsis of Clinical Dermatology. US, NY: ISBN 978-0-07-159975-7,MHID 0-07-159975-4.

3. Morimoto S, Kumahara Y (1985) A patient with psoriasis cured by 1 alpha-hydroxyvitamin D3. Med J Osaka Univ 35:51-54

4. Kragballe K (1990) Combination of topical calcipotriol (MC 903) and UVB radiation for psoriasis vulgaris. Dermatologica 181: 211-214

5. Milde P, Hauser U, Simon T, Mall G, Ernst V, Haussler MR et al (1991) Expression of 1,25-dihydroxyvitamin D3 receptors in normal and psoriatic skin. J Invest Dermatol 97:230-239. doi: 10.1111/1523-1747.ep12480255

6. Tsoi LC, Spain SL, Knight J, Ellinghaus E, Stuart PE, Capon F et al (2012) Identification of 15 new psoriasis susceptibility loci highlights the role of innate immunity. Nat Genet 44:1341-1348. doi:10.1038/ng.2467

7. Capon F, Semprini S, Chimenti S, Fabrizi G, Zambruno G, Murgia S et al (2001) Fine mapping of the PSORS4 psoriasis susceptibility region on chromosome 1q21. J Invest Dermatol 116:728-730. doi:10.1046/j.15231747.2001.01311.x

8. Austin HR1, Hoss E1, Batie SF1, Moffet EW1, Jurutka PW2, Haussler MR1, Whitfield GK3.Regulation of late cornified envelope genes relevant to psoriasis risk by plant-derived cyanidin.

9. Huffmeier U, Bergboer JG, Becker T, Armour JA, TraupeH,Estivill X et al (2010) Replication of LCE3CLCE3B CNV as arisk factor for psoriasis and analysis of interaction with othergenetic risk factors. $\mathrm{J}$ Invest Dermatol 130:979-984. doi:10.1038/jid.2009.385

10. Marshall D, Hardman MJ, Nield KM, Byrne C (2001) Differentially expressed late constituents of the epidermal cornified envelope. ProcNatlAcadSci USA 98:13031-13036. doi: 10.1073/pnas.231489198

11. de Cid R, Riveira-Munoz E, Zeeuwen PL, Robarge J, Liao W,Dannhauser EN et al (2009) Deletion of the late cornified envelopeLCE3B and LCE3C genes as a susceptibility factor forpsoriasis. Nat Genet 41:211-215. doi:10.1038/ng.313

12. Bergboer JG, Tjabringa GS, Kamsteeg M, van Vlijmen-Willems IM, Rodijk-Olthuis D, Jansen PA et al (2011) Psoriasis risk genes of the late cornified envelope-3 group are distinctly expressed compared with genes of other LCE groups. Am J Pathol 178:1470-1477.doi: 10.1016/j.ajpath.2010.12.017 